
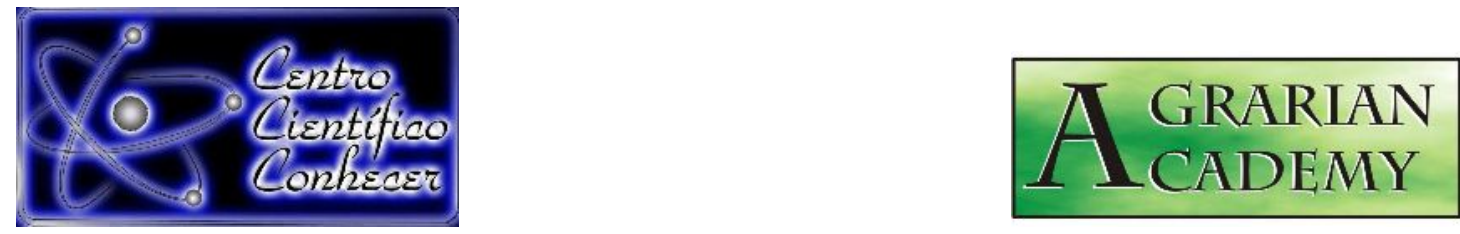

\title{
LEVANTAMENTO FITOSSOCIOLÓGICO DE PLANTAS DANINHAS EM PRÉ- COLHEITA DO MILHO NA INTEGRAÇÃO LAVOURA PECUÁRIA FLORESTA
}

João Carlos Ribeiro Neto ${ }^{1}$, Natália Monte Negro dos Santos Jacobi ${ }^{1}$, Mateus Henrique dos Santos Diniz ${ }^{1}$, Reinaldo Silva Oliveira Canuto², Débora Maria Ferreira Oliveira Canuto ${ }^{3}$

${ }^{1}$ Graduando (a) em Engenharia Agronômica pelo Instituto Federal de Educação,

Ciência e Tecnologia do Triângulo Mineiro, Campus Uberlândia, MG.

${ }^{2}$ Doutor em Agronomia (Fitotecnia) e professor do Instituto Federal de Educação, Ciência e Tecnologia do Triângulo Mineiro, Campus Uberlândia, Uberlândia, MG. Email: reinaldo@iftm.edu.br

${ }^{3}$ Doutora em Ciências e professora da Universidade Presidente Antônio Carlos, Campus Delta, Uberlândia, MG

Recebido em: 20/11/2019 - Aprovado em: 15/12/2019 - Publicado em: 30/12/2019 DOI: 10.18677/Agrarian_Academy_2019b9

\begin{abstract}
RESUMO
As plantas daninhas representam um fator prejudicial para a cultura do milho inserido no sistema de Integração Lavoura Pecuária Floresta (ILPF). Neste sistema, diferentes espécies florestais podem integrá-lo e pouco se conhece sobre as influências destas espécies na população de plantas infestantes. Assim, o objetivo deste trabalho foi realizar o levantamento fitossociológico de plantas daninhas em pré-colheita do milho cultivado em sistema de ILPF composto pelo eucalipto e pelo mogno africano. O levantamento foi realizado na Fazenda Sobradinho do IFTM Campus Uberlândia por meio do método do quadrado inventário de $1,0 \mathrm{~m} \times 1,0 \mathrm{~m}$, colocado aleatoriamente nas linhas de cultivo de milho. A amostragem foi realizada em dois ambientes de ILPF (milho + eucalipto e milho + mogno africano) e em uma terceira área adjacente ao ILPF, onde foram amostradas as plantas daninhas no milho cultivado sob sistema convencional, totalizando 30 amostras. Em cada amostra foram quantificadas e identificadas as espécies presentes. Foram avaliadas as seguintes características fitossociológicas: frequência, densidade e abundância (absolutas e relativas) e índice de valor de importância. A comunidade infestante presente nas áreas de estudo foi composta por 29 espécies distribuídas em 13 famílias, com destaque para Asteraceae e Fabaceae. As espécies de plantas daninhas predominantes (com maior índice de valor de importância) em cultivo convencional de milho e na área de ILPF com milho cultivado na entrelinha do eucalipto foram Commelina benghalensis e Neonotonia wightii. Já em milho cultivado com mogno africano, o milho foi infestado predominantemente pela Conyza bonariensis.
\end{abstract}

PALAVRAS-CHAVE: Fitossociologia; ILPF; Zea mays (L.). 


\title{
PHYTOSOCIOLOGICAL SURVEY OF WEEDS IN CORN PRE-HARVEST IN THE INTEGRATION CROP LIVESTOCK FOREST
}

\begin{abstract}
Weeds represent a detrimental factor for corn crop inserted in the Forest Livestock Integration System (ILPF). In this system, different forest species can be integrated and little is known about the influence of these species on the weed population. Thus, the objective of this work was to carry out the phytosociological survey of weeds in the pre-harvest of corn cultivated in the ILPF with eucalyptus and african mahogany. The survey was carried out at the Sobradinho Farm of the IFTM Campus of Uberlândia, using the square inventory method of $1.0 \mathrm{~m} \times 1.0 \mathrm{~m}$, placed randomly in the maize cultivation lines. Sampling was performed in two ILPF environments (maize + eucalyptus and maize + african mahogany) and in a third area adjacent to the ILPF, where weeds were sampled in corn in a conventional system, totaling 30 samples. In each sample were quantified and identified the species present. The following phytosociological adjustments were applied: frequency, density and abundance (absolute and relative) and importance value index. The weed community was composed of 29 species distributed in 13 families, especially Asteraceae and Fabaceae. The predominant weeds species (with higher value index) in conventional maize cultivation and in the ILPF area with eucalyptus and corn were Commelina benghalensis and Neonotonia wightii. In maize cultivated with African mahogany, maize was predominantly infested by Conyza bonariensis.
\end{abstract}

KEYWORDS: ILPF; Phytosociology; Zea mays (L.).

\section{INTRODUÇÃO}

A integração Lavoura-Pecuária-Floresta (ILPF) apresenta-se como uma tecnologia acessível para renovação e recuperação de áreas degradadas causadas pelo manejo inapropriado. Além disso, possibilita a produção de grãos em conjunto com a exploração de atividades silviculturais demonstrando viabilidade econômicofinanceira de um conjunto agroflorestal biodiverso capaz de estimular a geração de renda (FERREIRA et al., 2018; MARTINELLI et al., 2019).

As espécies arbóreas utilizadas neste sistema proporcionam melhorias ao ambiente de produção agrícola como a proteção do solo, a liberação de nutrientes e a deposição de matéria orgânica oriunda dos restos vegetais das árvores. Adicionalmente, são alternativas para sequestrarem o dióxido de carbono (SOUZA et al., 2018).

O mogno africano (Khaya ivorensis) e o eucalipto (Eucalyptus spp.) são opções para o cultivo em sistema de ILPF devido aos seus atributos de boa adaptabilidade ao cultivo, rápido crescimento, altas taxas de sobrevivência após o plantio, bom crescimento em altura e alto valor comercial da madeira, bastante estimada no mercado interno e externo (SALES et al., 2017; LOPES et al., 2018; FERREIRA et al., 2018).

As plantas daninhas estão entre as causas que podem interferir negativamente no desenvolvimento das culturas agrícolas que integram o ILPF. A redução na produtividade de grãos ocorre devido à matocompetição resultante da disputa por água, luz, nutrientes e ainda devido aos efeitos alelopáticos (CASTRO et al., 2013; FONTES et al., 2011).

$\mathrm{Na}$ cultura do milho, em campo experimental da Embrapa Milho e Sorgo em Sete Lagoas-MG, foram relatadas as seguintes plantas daninhas aos 60 dias após a 
semeadura: Leonotis nepetifolia, Digitaria horizontalis, Cyperus rotundus, Richardia brasiliensis, Ageratum conyzoides e Amaranthus retroflexus (NOCE et al., 2006). Embora estas espécies tenham sido identificadas por Noce et al. (2006), é importante ressaltar que a população de plantas daninhas pode variar de uma região para outra em função de uma série de fatores como o histórico de manejo do solo, das culturas em rotação e/ou sucessão, do "banco de sementes" de plantas daninhas no solo, do clima, entre outros fatores. Sendo assim, em cada sistema de cultivo, é necessário realizar um levantamento de plantas daninhas para averiguar quais espécies necessitam de maior atenção quanto ao manejo.

O rápido desenvolvimento de plantas infestantes também reduz o rendimento da colhedora em função das interrupções constantes para a limpeza da máquina agrícola. Esse procedimento é necessário para evitar a presença de impurezas junto aos grãos de milho, pois o adensamento prejudica as operações mecanizadas (MANTOVANI, 1985; BALBINO et al., 2011).

Outro fator a ser considerado e que pode ser importante na composição das espécies de plantas daninhas presentes na cultura do milho é o sombreamento exercido pelas espécies florestais que constituem o ILPF. Devido à adaptabilidade diferenciada das plantas daninhas em função dos variados níveis de sombreamento (IKEDA et al., 2016), é possível encontrar uma comunidade de competidoras na cultura do milho que variam de acordo com a espécie florestal e, consequentemente, a interferência na produção de grãos pode ser alterada.

Ao empregar o sistema de produção de ILPF, verifica-se a redução da deterioração física, química e biológica do solo em função das múltiplas culturas agrícolas que podem ser exploradas no local, inclusive com a inserção de uma cultura de alta relação $\mathrm{C} / \mathrm{N}$ que favoreça a supressão do desenvolvimento de plantas daninhas (FALEIRO; FARIA NETO, 2008; CUNHA, 2017). O controle cultural por meio da estruturação do sistema de plantio direto é uma estratégia viável para a redução do banco de sementes das plantas daninhas da parte superficial do solo.

A rotação de culturas, inerente ao plantio direto, é um eficiente manejo, porque previne o surgimento de grandes populações das plantas infestantes adaptadas à determinadas culturas. A utilização de espaçamento adequado na cultura do milho, onde se tenha uma boa cobertura do solo no estágio de pleno desenvolvimento vegetativo, permite uma vantagem competitiva do milho em relação às ervas daninhas (KARAM et al., 2006), sendo também um manejo a ser empregado.

Portanto, o objetivo deste trabalho foi realizar o levantamento fitossociológico de plantas daninhas presentes em pré-colheita de milho cultivado em sistema agrossilvipastoril composto pelo eucalipto e pelo mogno africano como componentes florestais do ILPF.

\section{MATERIAL E MÉTODOS}

O trabalho foi realizado na área de Integração Lavoura-Pecuária-Floresta, situada a $18^{\circ} 46^{\prime}$ ' $45^{\prime \prime}$ de latitude Sul e $48^{\circ} 17^{\prime} 38^{\prime \prime}$ de longitude Oeste na Fazenda Sobradinho e altitude média de $730 \mathrm{~m}$, de propriedade do Instituto Federal de Educação, Ciência e Tecnologia do Triângulo Mineiro, no município de Uberlândia, MG. De acordo com a classificação de Köppen, o clima da região é Aw, com verões chuvosos e invernos secos (MENDES, 2001). O solo da região é caracterizado como um LATOSSOLO VERMELHO Distrófico típico, de textura muito argilosa e horizonte A moderado (EMBRAPA, 2013). 
A área possui cerca de 5 hectares, onde foi implantado há quatro anos 0 Sistema Agrossilvipastoril, possuindo cerca de sete espécies florestais distribuídas em 10 linhas, com espaçamento entre plantas de dois metros e entre linha 15 metros. Nas entre linhas realizou-se o plantio de milho híbrido no dia 13 de novembro de 2017, com espaçamento de 0,8 metros entre linhas e com quatro sementes por metro.

Aos 10 dias antes da semeadura do milho, foi realizada a aplicação do herbicida glifosato e 2,4-D para a dessecação das plantas daninhas. Durante o desenvolvimento do milho, não foi realizada aplicação de herbicida pós-emergente.

O levantamento das plantas daninhas foi realizado na segunda quinzena de abril de 2018. Nesse período, o milho já havia atingido o ponto de maturidade fisiológica e seria colhido uma semana após o levantamento das plantas daninhas. Essa amostragem foi realizada na cultura do milho cultivada em dois ambientes de ILPF (com eucalipto e com mogno africano). Em uma terceira área adjacente ao ILPF, também foram amostradas as plantas daninhas no milho cultivado sob sistema convencional para produção de grãos. Para cada área foram utilizadas 10 amostragens, utilizando o método do quadrado inventário (BRAUN-BLANQUET, 1979) totalizando 30 amostras. Foi utilizado um quadrado de $1,0 \mathrm{~m} \times 1,0 \mathrm{~m}$, com área total de $1 \mathrm{~m}^{2}$, colocado aleatoriamente nas linhas de cultivo pelo método do caminhamento em ziguezague.

Para cada amostra, as plantas daninhas foram quantificadas e posteriormente cortadas rente ao solo, acondicionadas em sacos plásticos e armazenada em caixa térmica a fim de evitar a perda de umidade. Ao término do procedimento, a caixa contendo as plantas daninhas foram levadas ao laboratório.

No Laboratório de Solos do Instituto Federal de Educação, Ciência e Tecnologia do Triângulo Mineiro, Campus Uberlândia, as plantas foram classificadas quanto a família, gênero e espécie, com auxílio do Manual de identificação e controle de plantas daninhas: plantio direto e convencional (LORENZI, 2014). Após a quantificação das espécies de plantas daninhas, foi possível calcular os parâmetros fitossociológicos propostos por Müeller-Dombois e Ellenberg (1974):

Frequência (índice de repetição das espécies nos quadrados):

$$
\mathrm{F}=\frac{\text { Número de parcelas que contém a aspécie }}{\text { Total de parcelas utilizadas }}
$$

Densidade (índice do número de indivíduos de uma mesma espécie em todos os quadrados):

$$
\mathrm{D}=\frac{\text { Total de individuos por espécie }}{\text { Area total coletada }}
$$

Abundância (agrupamento das espécies nos diferentes pontos da área total):

$$
\mathrm{A}=\frac{\text { Total de individuos por especie }}{\text { Total de parcelas contendo a espécie }}
$$

Frequência relativa:

$$
\mathrm{Fr}=\frac{\text { Frequência da espécie } x 100}{\text { Frequência total de todas as aspécies }}
$$

Densidade relativa:

$$
\mathrm{Dr}=\frac{\text { Densidade da espécie } \mathrm{X} 100}{\text { Densidade total de todas as espécies }}
$$


Abundância relativa (relaciona uma espécie a todas as demais encontradas nas áreas):

$$
\mathrm{Ar}=\frac{\text { Abundância da espécie } X 100}{\text { Abundância total de todas as espécies }}
$$

Índice de valor de importância:

$$
\mathrm{IVI}=\mathrm{Fr}+\mathrm{Dr}+\mathrm{Ar}
$$

\section{RESULTADOS E DISCUSSÃO}

Após a identificação e a quantificação foi possível verificar a comunidade de plantas daninhas presentes na cultura do milho sob sistema convencional de produção de grãos e em dois ambientes de ILPF. No conjunto dos três ambientes foram encontradas 29 espécies de plantas daninhas, distribuídas em 13 famílias (Quadro 1).

QUADRO 1. Relação das espécies de plantas daninhas identificadas no levantamento fitossociológico na cultura do milho sob sistema convencional de produção de grãos e em sistema ILPF distribuídas em família, nome comum e nome

\begin{tabular}{|c|c|c|}
\hline Família & Nome Comum & Nome científico \\
\hline Amaranthaceae & Erva de santa maria & Chenopodium ambrosioides \\
\hline \multirow{6}{*}{ Asteraceae } & Buva & Conyza bonariensis \\
\hline & Marcela branca & Gamochaeta coarctata \\
\hline & Serralha & Sonchus oleraceus \\
\hline & Erva-de-touro & Tridax procumbens \\
\hline & Erva fresca & Porophyllum ruderale \\
\hline & Mentrasto & Ageratum conyzoides \\
\hline \multirow{2}{*}{ Commelinaceae } & Trapoeraba & Commelina benghalensis \\
\hline & Erva de Santa Luzia & Commelina erecta \\
\hline Convolvulaceae & Corda-de-viola & Ipomoea triloba \\
\hline Cyperaceae & Tiririca & Cyperus iria \\
\hline Euphorbiaceae & Mamona & Ricinus communis \\
\hline \multirow{6}{*}{ Fabaceae } & Anileira & Indigofera hirsuta \\
\hline & Soja perene & Neonotonia wightii \\
\hline & Angiquinho & Aeschynomene denticulata \\
\hline & Carrapicho beiço de boi & Desmodium tortuosum \\
\hline & Xique-xique & Crotalaria incana \\
\hline & Fedegoso & Senna obtusifolia \\
\hline \multirow{4}{*}{ Malvaceae } & Guanxuma & Sida cordifolia \\
\hline & Vassourinha & Sida rhombifolia \\
\hline & Guanxuma-dourada & Sida urens \\
\hline & Guanxuma branca & Sida glaziovii \\
\hline Phyllantaceae & Quebra pedra & Phyllanthus tenellus \\
\hline \multirow{3}{*}{ Poaceae } & Braquiária & Urochloa decumbens \\
\hline & Grama-seda & Cynodon dactylon \\
\hline & Capim colonião & Panicum maximum \\
\hline Rubiaceae & Erva quente & Spermacoce latifolia \\
\hline Sapindaceae & Balãozinho & Cardiospermum halicacabum \\
\hline Solanaceae & Joá-bravo & Solanum sisymbrifolium \\
\hline
\end{tabular}
científico, na região da Fazenda Sobradinho, Uberlândia, MG. 
Dentre as famílias, as que apresentaram maior número de espécies de plantas daninhas foram Asteraceae e Fabaceae, com um total de seis espécies para cada, seguidas de Malvaceae e Poaceae, com um total de quatro e três espécies para cada família, respectivamente. As famílias Asteraceae e Fabaceae, totalizam juntas cerca de $42 \%$ do total das espécies de plantas daninhas encontradas nos ambientes avaliados.

Os cálculos referentes ao levantamento fitossociológico realizado no milho cultivado convencionalmente evidenciaram a predominância das espécies Neonotonia wightii e Commelina benghalensis. A primeira espécie apresentou maior frequência relativa $(15,63 \%)$ e a segunda apresentou os maiores valores de densidade relativa e abundância relativa $(47,12$ e $29,73 \%$, respectivamente) (Tabela 1).

TABELA 1. Número de indivíduos (NI), número de presença em quadrados (NQ), frequência $(F)$, densidade $(D)$, abundância $(A)$, frequência relativa $(F r)$, densidade relativa (Dr) e abundância relativa (Ar) das espécies de plantas daninhas presentes na cultura do milho em sistema convencional de produção de grãos, na região da Fazenda Sobradinho, Uberlândia, MG.

\begin{tabular}{lcccccccc}
\hline \multicolumn{1}{c}{ Espécies } & $\mathrm{NI}$ & $\mathrm{NQ}$ & $\mathrm{F}$ & $\begin{array}{c}\mathrm{D} \\
\mathrm{pl} / \mathrm{m}^{2}\end{array}$ & $\mathrm{~A}$ & $\mathrm{Fr}$ & $\mathrm{Dr}$ & $\mathrm{Ar}$ \\
\hline Indigofera hirsuta & 6 & 2 & 0,20 & 0,60 & 3,00 & 3,13 & 1,57 & 4,46 \\
Commelina benghalensis & 180 & 9 & 0,90 & 18,00 & 20,00 & 14,06 & 47,12 & 29,73 \\
Sida cordifolia. & 22 & 8 & 0,80 & 2,20 & 2,75 & 12,50 & 5,76 & 4,09 \\
Urochloa decumbens & 24 & 8 & 0,80 & 2,40 & 3,00 & 12,50 & 6,28 & 4,46 \\
Neonotonia wightii & 96 & 10 & 1,00 & 9,60 & 9,60 & 15,63 & 25,13 & 14,27 \\
Commelina erecta & 4 & 1 & 0,10 & 0,40 & 4,00 & 1,56 & 1,05 & 5,95 \\
Conyza bonariensis & 15 & 2 & 0,20 & 1,50 & 7,50 & 3,13 & 3,93 & 11,15 \\
Sida rhombifolia & 17 & 7 & 0,70 & 1,70 & 2,43 & 10,94 & 4,45 & 3,61 \\
Gamochaeta coarctata & 1 & 1 & 0,10 & 0,10 & 1,00 & 1,56 & 0,26 & 1,49 \\
Sonchus oleraceus & 1 & 1 & 0,10 & 0,10 & 1,00 & 1,56 & 0,26 & 1,49 \\
Cardiospermum & & & & & & & & \\
halicacabum & 1 & 1 & 0,10 & 0,10 & 1,00 & 1,56 & 0,26 & 1,49 \\
Solanum sisymbrifolium & 1 & 1 & 0,10 & 0,10 & 1,00 & 1,56 & 0,26 & 1,49 \\
Sida urens & 2 & 2 & 0,20 & 0,20 & 1,00 & 3,13 & 0,52 & 1,49 \\
Aeschynomene denticulata & 1 & 1 & 0,10 & 0,10 & 1,00 & 1,56 & 0,26 & 1,49 \\
Tridax procumbens & 2 & 2 & 0,20 & 0,20 & 1,00 & 3,13 & 0,52 & 1,49 \\
Ricinus communis & 2 & 1 & 0,10 & 0,20 & 2,00 & 1,56 & 0,52 & 2,97 \\
Ipomoea triloba & 1 & 1 & 0,10 & 0,10 & 1,00 & 1,56 & 0,26 & 1,49 \\
Porophyllum ruderale & 1 & 1 & 0,10 & 0,10 & 1,00 & 1,56 & 0,26 & 1,49 \\
Desmodium tortuosum & 1 & 1 & 0,10 & 0,10 & 1,00 & 1,56 & 0,26 & 1,49 \\
Cyperus iria & 1 & 1 & 0,10 & 0,10 & 1,00 & 1,56 & 0,26 & 1,49 \\
Ageratum conyzoides & 1 & 1 & 0,10 & 0,10 & 1,00 & 1,56 & 0,26 & 1,49 \\
Não identificada & 2 & 2 & 0,20 & 0,20 & 1,00 & 3,13 & 0,52 & 1,49 \\
\hline \multicolumn{1}{c}{ TOTAL } & 382 & 64 & 6,40 & 38,20 & 67,28 & 100 & 100 & 100 \\
\hline
\end{tabular}

A composição florística observada no milho cultivado em área de ILPF com eucalipto também foi majoritariamente representada pelas espécies $N$. wightii e $C$. benghalensis. Nesta área, a espécie $N$. wightii apresentou a maior frequência e densidade relativas $(15,25$ e $38,46 \%$, respectivamente) comparada às demais 
espécies. Entretanto, a $C$. benghalensis foi a espécie de planta daninha com maior valor de abundância relativa (27,92\%) (Tabela 2$)$.

TABELA 2. Número de indivíduos (NI), número de presença em quadrados (NQ), frequência $(F)$, densidade $(D)$, abundância $(A)$, frequência relativa $(F r)$, densidade relativa (Dr) e abundância relativa (Ar) das espécies de plantas daninhas presentes na cultura do milho sob sistema ILPF composto por eucalipto como componente florestal, na região da Fazenda Sobradinho, Uberlândia, MG.

\begin{tabular}{|c|c|c|c|c|c|c|c|c|}
\hline Espécies & $\mathrm{NI}$ & $\mathrm{NQ}$ & $\mathrm{F}$ & $\begin{array}{c}\mathrm{D} \\
\mathrm{pl} / \mathrm{m}^{2}\end{array}$ & $A$ & $\mathrm{Fr}$ & $\begin{array}{l}\mathrm{Dr} \\
-\%\end{array}$ & $\mathrm{Ar}$ \\
\hline Commelina benghalensis & 83 & 8 & 0,80 & 8,30 & 10,38 & 13,56 & 35,47 & 27,92 \\
\hline Urochloa decumbens & 14 & 8 & 0,80 & 1,40 & 1,75 & 13,56 & 5,98 & 4,71 \\
\hline Sida rhombifolia & 18 & 8 & 0,80 & 1,80 & 2,25 & 13,56 & 7,69 & 6,05 \\
\hline Neonotonia wightii & 90 & 9 & 0,90 & 9,00 & 10,00 & 15,25 & 38,46 & 26,91 \\
\hline Sida urens & 4 & 4 & 0,40 & 0,40 & 1,00 & 6,78 & 1,71 & 2,69 \\
\hline Aeschynomene denticulata & 3 & 2 & 0,20 & 0,30 & 1,50 & 3,39 & 1,28 & 4,04 \\
\hline Cynodon dactylon & 2 & 2 & 0,20 & 0,20 & 1,00 & 3,39 & 0,85 & 2,69 \\
\hline Sida glaziovii & 1 & 1 & 0,10 & 0,10 & 1,00 & 1,69 & 0,43 & 2,69 \\
\hline Ipomoea triloba & 1 & 1 & 0,10 & 0,10 & 1,00 & 1,69 & 0,43 & 2,69 \\
\hline Chenopodium ambrosioides & 1 & 1 & 0,10 & 0,10 & 1,00 & 1,69 & 0,43 & 2,69 \\
\hline Cyperus iria & 2 & 2 & 0,20 & 0,20 & 1,00 & 3,39 & 0,85 & 2,69 \\
\hline Conyza bonariensis & 2 & 2 & 0,20 & 0,20 & 1,00 & 3,39 & 0,85 & 2,69 \\
\hline Crotalaria incana & 2 & 2 & 0,20 & 0,20 & 1,00 & 3,39 & 0,85 & 2,69 \\
\hline Tridax procumbens & 1 & 1 & 0,10 & 0,10 & 1,00 & 1,69 & 0,43 & 2,69 \\
\hline Não identificada & 1 & 1 & 0,10 & 0,10 & 1,00 & 1,69 & 0,43 & 2,69 \\
\hline TOTAL & 234 & 59 & 5,90 & 23,40 & 37,16 & 100 & 100 & 100 \\
\hline
\end{tabular}

A espécie de maior frequência no presente trabalho foi $N$. wightii, seguida da Sida rhombifolia, Urochloa decumbens e $C$. benghalensis $(0,90 ; 0,80 ; 0,80$ e 0,80 ; respectivamente), diferindo das espécies encontradas por Kaneko et al. (2018) em uma área com povoamento do clone I144, de um híbrido de Eucalyptus urophyla $\mathrm{x}$ Eucalyptus grandis, na cidade de Chapadão do Sul-MS, que foram Chamaesyce hyssopifolia, seguida da S. rhombifolia, C. benghalensis e Acanthospermum australe $(0,92 ; 0,67 ; 0,50$ e 0,33 ; respectivamente) para cinco metros entrelinhas e Richardia brasiliensis e $A$. australe (ambas com 0,56), Leonotis nepetifolia, $C$. benghalensis e $S$. rhombifolia (respectivamente com 0,$50 ; 0,47$ e 0,44 ) para quatro metros. Dentre essas espécies, destacou-se a família Malvaceae ( $S$. rhombifolia), sendo de difícil controle e apresentando alto potencial de competição em reboleiras (BIANCO et al., 2014) e Commelinaceae ( $C$. benghalensis), tendo preferência por ambientes úmidos e sombreados (VOLL et al., 1997).

No levantamento realizado no milho cultivado em área de ILPF com mogno africano, a maior frequência relativa foi observada para a espécie $N$. wightii $(14,29 \%)$. Diferentemente das outras áreas de cultivo de milho, nesta foram verificados maiores valores de densidade e abundância relativas para a espécie Conyza bonariensis (48,32\% e $36,87 \%$, respectivamente) (Tabela 3 ). 
TABELA 3. Número de indivíduos (NI), número de presença em quadrados (NQ)FIGUR, frequência $(F)$, densidade $(D)$, abundância $(A)$, frequência relativa $(\mathrm{Fr})$, densidade relativa ( $\mathrm{Dr}$ ) e abundância relativa (Ar) das espécies de plantas daninhas presentes na cultura do milho sob sistema ILPF composto por mogno africano como componente florestal, na região da Fazenda Sobradinho, Uberlândia, MG.

\begin{tabular}{lcccccccc}
\hline \multicolumn{1}{c}{ Espécies } & $\mathrm{NI}$ & $\mathrm{NQ}$ & $\mathrm{F}$ & $\mathrm{D}$ & $\mathrm{A}$ & $\mathrm{Fr}$ & $\mathrm{Dr}$ & $\mathrm{Ar}$ \\
& & & & $\mathrm{pl} / \mathrm{m}^{2}$ & & $----------\%$ & -------- \\
\hline Commelina benghalensis. & 26 & 5 & 0,50 & 2,60 & 5,20 & 7,14 & 4,38 & 5,34 \\
Aeschynomene denticulata & 2 & 2 & 0,20 & 0,20 & 1,00 & 2,86 & 0,34 & 1,03 \\
Sida rhombifolia & 66 & 9 & 0,90 & 6,60 & 7,33 & 12,86 & 11,11 & 7,54 \\
Sida cordifolia & 11 & 4 & 0,40 & 1,10 & 2,75 & 5,71 & 1,85 & 2,83 \\
Conyza bonariensis & 287 & 8 & 0,80 & 28,70 & 35,88 & 11,43 & 48,32 & 36,87 \\
Crotalaria incana & 3 & 3 & 0,30 & 0,30 & 1,00 & 4,29 & 0,51 & 1,03 \\
Urochloa decumbens & 19 & 7 & 0,70 & 1,90 & 2,71 & 10,00 & 3,20 & 2,79 \\
Chenopodium ambrosioides & 1 & 1 & 0,10 & 0,10 & 1,00 & 1,43 & 0,17 & 1,03 \\
Spermacoce latifolia & 1 & 1 & 0,10 & 0,10 & 1,00 & 1,43 & 0,17 & 1,03 \\
Ricinus communis & 17 & 7 & 0,70 & 1,70 & 2,43 & 10,00 & 2,86 & 2,50 \\
Phyllanthus tenellus & 6 & 4 & 0,40 & 0,60 & 1,50 & 5,71 & 1,01 & 1,54 \\
Commelina erecta & 3 & 2 & 0,20 & 0,30 & 1,50 & 2,86 & 0,51 & 1,54 \\
Senna obtusifolia & 3 & 3 & 0,30 & 0,30 & 1,00 & 4,29 & 0,51 & 1,03 \\
Panicum maximum & 34 & 2 & 0,20 & 3,40 & 17,00 & 2,86 & 5,72 & 17,47 \\
Tridax procumbens & 3 & 1 & 0,10 & 0,30 & 3,00 & 1,43 & 0,51 & 3,08 \\
Cyperus iria & 2 & 1 & 0,10 & 0,20 & 2,00 & 1,43 & 0,34 & 2,06 \\
\hline \multicolumn{1}{c}{ TOTAL } & 594 & 70 & 7,00 & 59,40 & 97,30 & 100 & 100 & 100 \\
\hline
\end{tabular}

Após o levantamento dos valores de frequência, densidade e abundância (absolutas e relativas), foi determinado o índice de valor de importância (IVI), que indica as espécies de plantas daninhas que devem receber maior atenção quanto às estratégias de controle a serem adotadas nas áreas de cultivo de milho (convencional ou ILPF).

Em área de cultivo de milho em sistema convencional, foi verificado a presença de maior índice de IVI para as espécies $C$. benghalensis e N. wightii, embora outras espécies apresentaram considerável índice: S. rhombifolia, Conyza bonariensis, Commelina erecta, U. decumbens, Sida cordifolia e Indigofera hirsuta (Figura 1). 


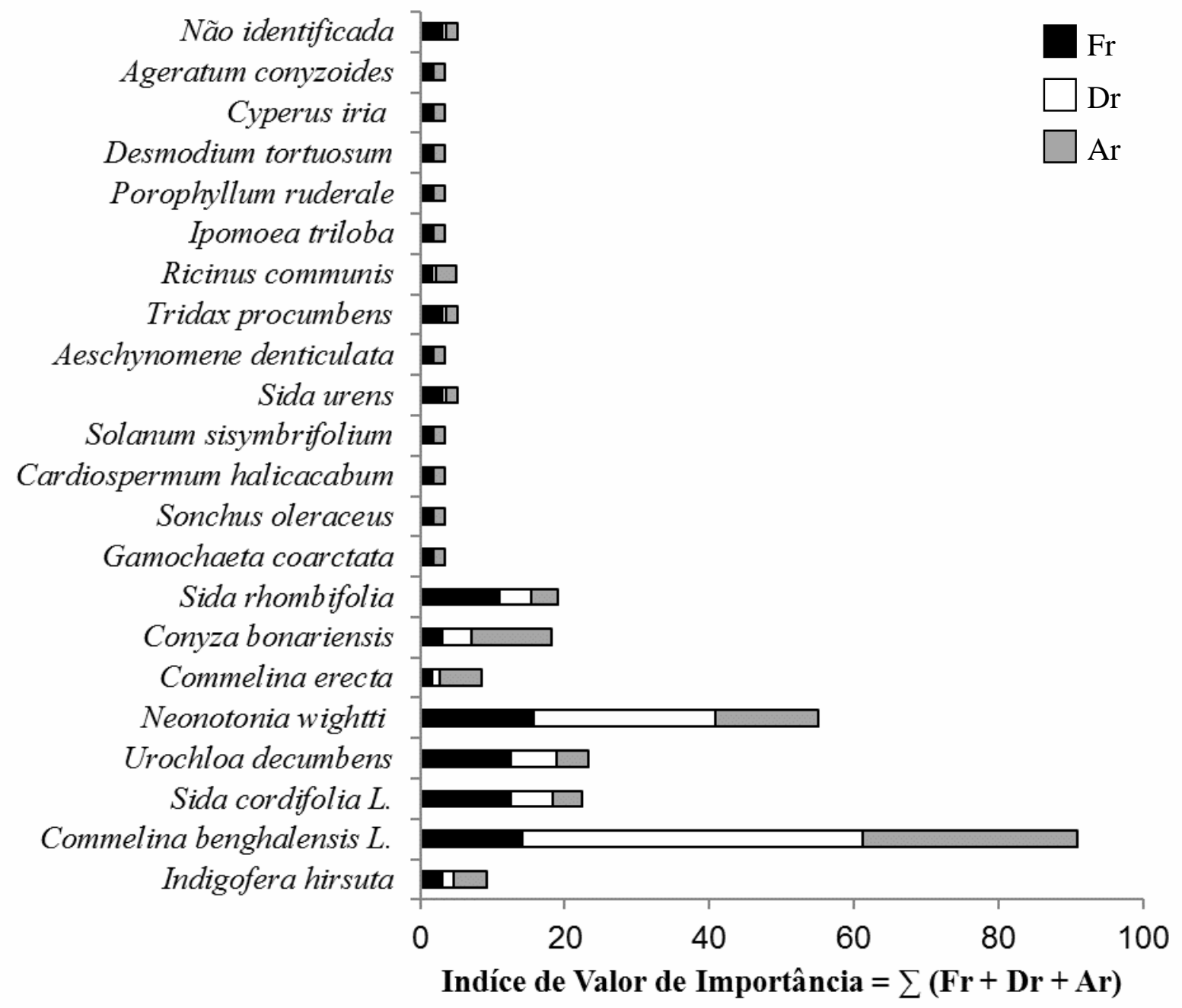

FIGURA 1. Índice de valor de importância das espécies de plantas daninhas presentes na cultura do milho em sistema convencional de produção de grãos, na região da Fazenda Sobradinho, Uberlândia, MG.

No milho cultivado na área de eucalipto, também foi verificada a presença de maior índice de IVI para as espécies $C$. benghalensis e $N$. wightii, As espécies de ocorrência secundária (com IVI a partir de 5\%) (Figura 2) foram as mesmas observadas em área de cultivo convencional de milho. Corroborando com o presente trabalho, Kaneko et al. (2018) também relataram que a espécie $C$. benghalensis apresentou maior índice de IVI em área de cultivo de eucalipto com maior sombreamento. 


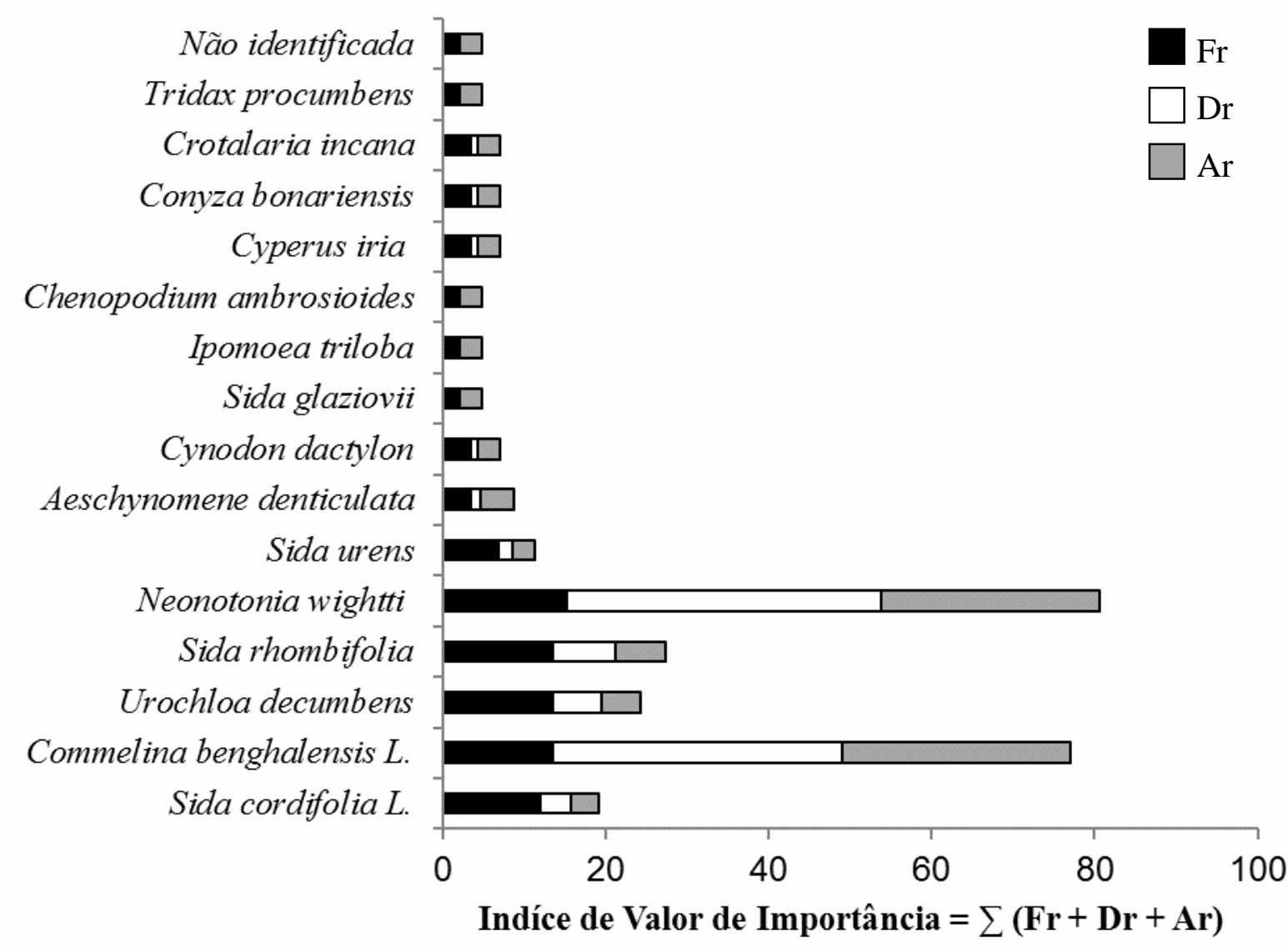

FIGURA 2. Índice de valor de importância das espécies de plantas daninhas presentes na cultura do milho sob sistema ILPF composto por eucalipto como componente florestal, na região da Fazenda Sobradinho, Uberlândia, MG.

Em área de mogno africano, a cultura do milho foi infestada predominantemente por $C$. bonariensis (IVI $=96,62 \%$ ). Esta espécie de planta daninha se destacou, seguida das espécies $N$. wightii, S. rhombifolia e Panicum maximum (Figura 3). 


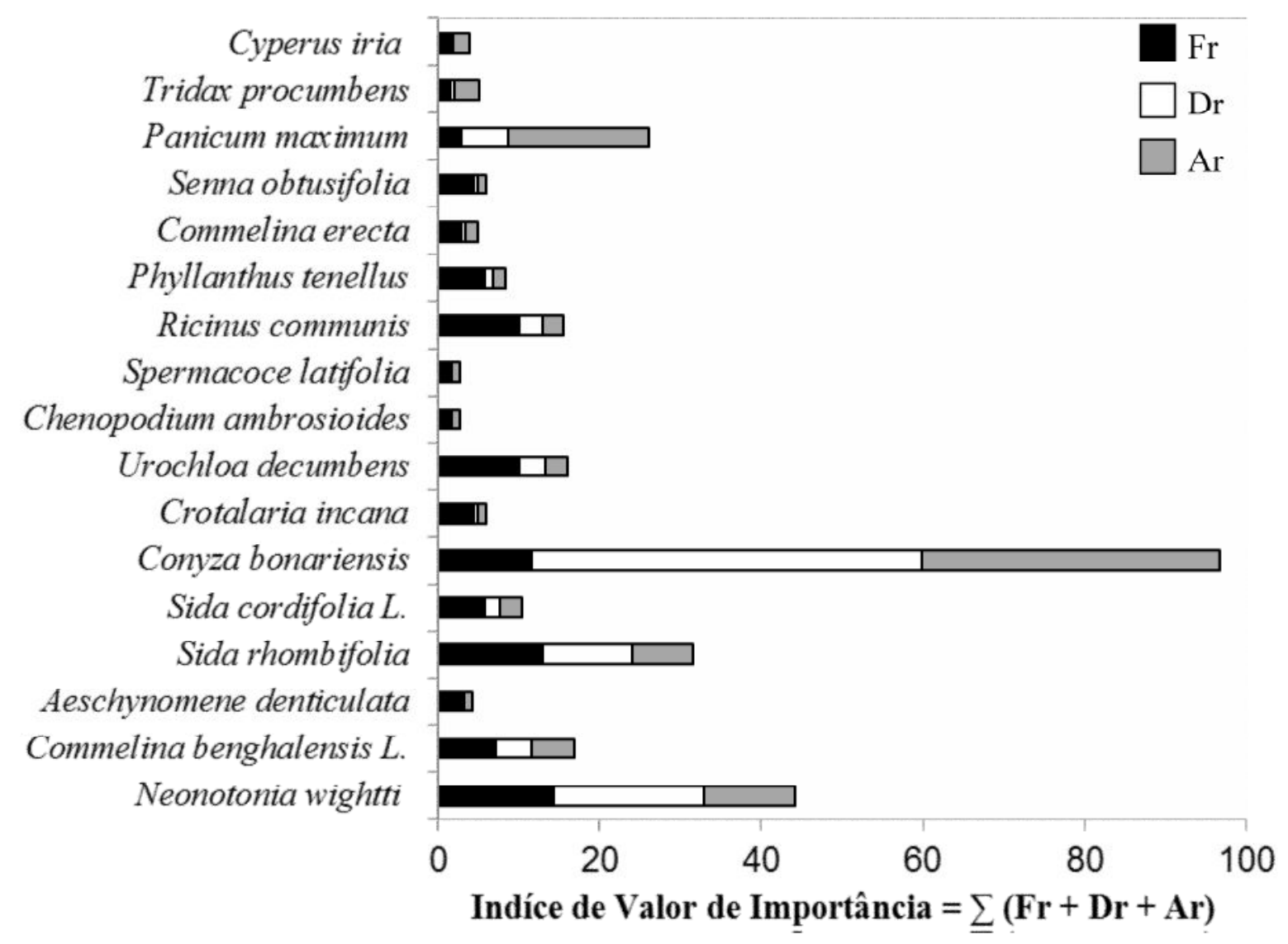

FIGURA 3. Índice de valor de importância das espécies de plantas daninhas presentes na cultura do milho sob sistema ILPF composto por mogno africano como componente florestal, na região da Fazenda Sobradinho, Uberlândia, MG.

Durante o levantamento das plantas daninhas nos diferentes sistemas de produção de milho, foi observada a presença de plantas infestantes em fase de préflorescimento ou florescimento ou, ainda, enchimento de grãos. Considerando presença das espécies $N$. wightii e $C$. benghalensis no milho em sistema de cultivo convencional e no milho na ILPF composta pelo eucalipto, é possível afirmar que o ambiente de produção pode ser comprometido caso não sejam adotadas medidas para a redução da população de ervas daninhas nestes locais após a colheita do milho.

Entre as possíveis estratégias a serem adotadas, há a aplicação de herbicidas como o glifosato e o 2,4-D, sendo esta mistura de pronto uso frequentemente utilizada pelos produtores rurais para a dessecação. Outra possível estratégia seria a utilização da roçadeira para impedir a produção de sementes das plantas daninhas que podem elevar a quantidade de sementes no solo e comprometer a sucessão de culturas anuais nas áreas de estudo.

$\mathrm{Na}$ cultura do milho conduzida em ILPF com mogno africano, foi verificada a elevada infestação pela $C$. bonariensis. Estudos posteriores devem ser realizados para verificar se há caso de resistência desta espécie em relação aos herbicidas glifosato e/ou 2,4-D, os quais têm sido utilizados com maior frequência neste ambiente de produção agrícola nas operações de dessecação. Mesmo que não seja verificado um caso de resistência aos herbicidas mencionados anteriormente, é 
necessário enfatizar que o glifosato possui menor eficácia no controle da $C$. bonariensis. No avançado estádio fenológico em que as plantas desta espécie se encontravam (o que é um fator agravante) seria necessário aplicar o herbicida 2,4-D somente após a brotação da erva daninha que seria previamente roçada. Portanto, em cada área, o levantamento fitossociológico realizado na pré-colheita do milho permitiu conhecer quais as espécies devem receber maior atenção quanto às estratégias de controle a serem adotadas.

\section{CONCLUSÃO}

As espécies de plantas daninhas predominantes (com maior índice de valor de importância) em cultivo convencional de milho e na área de ILPF com milho cultivado na entrelinha do eucalipto foram $C$. benghalensis e $N$. wightii. Já em milho cultivado com mogno africano, o milho foi infestado predominantemente pela $C$. bonariensis.

\section{REFERÊNCIAS}

BALBINO, L. C.; BARCELLOS, A. de O.; STONE, L. F. Marco referencial: Integração Lavoura-Pecuária-Floresta (ILPF). Brasília, DF: Embrapa, 2011. 130 p. Disponível em: <https://www.alice.cnptia.embrapa.br/bitstream/doc/923530/1/balbino01.pdf>.

BIANCO, S.; CARVALHO, L.B.; BIANCO, M. S. Crescimento e nutrição mineral de Sida rhombifolia. Planta Daninha, Viçosa-MG, v. 32, n. 2, p. 311-317, 2014. Disponível em: <http://dx.doi.org/10.1590/S0100-83582014000200008>. doi: 10.1590/S0100-83582014000200008

BRAUN-BLANQUET, J. Fitosociologia: bases para el estudio de las comunidades vegetales. Madrid: $\mathrm{H}$. Blume, 1979. $820 \mathrm{p}$.

CASTRO, G. S. A.; NEGRISOLI, E.; PERIM, L.; CRUSCIOL, C. A. C. Rotação adequada. Cultivar Grandes Culturas, Pelotas, v. 1, n. 1, p.12-14, 23 set. 2013. Disponível em: <https://www.grupocultivar.com.br/revistas/111>.

CUNHA, L. E. Estudo de viabilidade para implantação de sistemas de integração lavoura-pecuária-floresta (ILPF) em regiões de clusters florestais no Brasil. 2017. 45 f. TCC (Graduação) - Curso de Engenharia Florestal, Universidade de Brasília, Brasília, 2017. Disponível em: <http://bdm.unb.br/bitstream/10483/19015/1/2017_LaisErnestoCunha.pdf>.

EMBRAPA. Sistema Brasileiro de Classificação de Solos. 3. ed. Rev. Amp. Brasília, DF: Embrapa, 2013. 353p.

FALEIRO, F. G.; FARIA NETO, A. L. Savanas: desafios e estratégias para o equilíbrio entre sociedade, agronegócio e recursos naturais. Planaltina: Embrapa Cerrados, 2008. 1132 p. Disponível em: <https://www.embrapa.br/buscade-publicacoes/-/publicacao/570974/savanas-desafios-e-estrategias-para-oequilibrio-entre-sociedade-agronegocio-e-recursos-naturais>. 
FERREIRA, N. C. F.; NASCIMENTO, A. G.; SILVA, I. C.; CUNHA, S. D.; RAMOS, T. V. Deposição e Acúmulo de Serapilheira em sistema de ILPF no município de Ipameri - Goiás. In: CONGRESSO DE ENSINO, PESQUISA E EXTENSÃO DA UEG, 4., 2017, Ipameri. Anais do Congresso de Ensino, Pesquisa e Extensão da UEG. Ipameri: UEG, 2018. v. 4, p. 1 - 5. Disponível em: <https://www.anais.ueg.br/index.php/cepe/article/view/10626>.

FONTES, J. R. A.; PERIN, R.; SOUSA, J. N.; MARTINS, G. C.; SANTOS, A. M. B. Manejo Integrado de Plantas Daninhas em Pastagens na Integração LavouraPecuária-Floresta: plantas daninhas em pastagens da Amazônia. 37. ed. Manaus: Embrapa, $2011 . \quad 10 \quad$ p. $\quad$ Disponível <https://www.infoteca.cnptia.embrapa.br/infoteca/bitstream/doc/931301/1/CircTec37. pdf $>$.

IKEDA, F. S.; POLTRONIERI, F.; COSTA, W. B.; AZEVEDO, R. C. Comunidade de plantas daninhas em relação à distância de renque de eucalipto em sistema de ILPF em Mato Grosso. In: XXX Congresso Brasileiro da Ciência das Plantas Daninhas, 30, 2016, Curitiba. Embrapa Agrossilvipastoril. Resumo em Anais de Congresso (ALICE). Curitiba: Sociedade Brasileira da Ciência das Plantas Daninha, 2016. v. 50, p. $50 \quad$ - $50 . \quad$ Disponível em: https://www.alice.cnptia.embrapa.br/bitstream/doc/1055043/1/2016cpamtikedacomun idadeplantasdistanciarenqueilpf.pdf>.

KANEKO, J. A.; LIMA, S. F.; LIMA, A. P. L.; MARTINS, S. M.; SANTOS, D. M. C. L. Fitossociologia de plantas daninhas em eucalipto clonal com diferentes espaçamentos. Brazilian Applied Science Review, v. 2, n. 6, p. 2021-2036, 2018. Disponível em: <http://www.brjd.com.br/index.php/BASR/article/view/616/516>.

KARAM, D.; MELHORANÇA, A. L.; OLIVEIRA, M. F. Plantas Daninhas na Cultura do Milho. Circular Técnica 79. Sete Lagoas, MG. 2006. Disponível em: <http://www.cnpms.embrapa.br/protilp/artigos/Circ_79.pdf>.

LOPES, L. S. S.; RODE, R.; PAULETTO, D.; BALONEQUE, D. D.; SILVA, A. R.; SANTOS, K. N. F. Ajuste de modelos de taper e sortimento de toras de mogno africano em sistemas agroflorestais em Belterra, Pará. Revista Agroecossistemas, [s.I.], v. 10, n. 1, p.18-28, 11 nov. 2018. Universidade Federal do Pará. Disponível em: <http://dx.doi.org/10.18542/ragros.v10i1.5213>. doi: 10.18542/ragros.v10i1.5213

LORENZI, H. Manual de identificação e controle de plantas daninhas: plantio direto e convencional. 7. ed. Nova Odessa: Instituto Plantarum, 2014. 383 p.

MANTOVANI, E. C. A colheita mecânica do milho. São Paulo: Raízes, 1985. 3 p. Disponível em: <https://ainfo.cnptia.embrapa.br/digital/bitstream/item/67079/1/Colheitamecanica.pdf>.

MARTINELLI, G. C.; SCHLINDWEIN, M. M.; PADOVAN, M. P.; GIMENES, R. M. T. Decreasing uncertainties and reversing paradigms on the economic performance of agroforestry systems in Brazil. Land Use Policy, [s.I.], v. 80, p.274-286, jan. 2019. 
Disponível em: <https://doi.org/10.1016/j.landusepol.2018.09.019>. doi: 10.1016/j.landusepol.2018.09.019

MENDES, P. C. A gênese espacial das chuvas na cidade de Uberlândia (MG). Dissertação (Mestrado em Geografia). Universidade Federal de Uberlândia, Uberlândia, 2001.

MUELLER-DOMBOIS, D.; ELLENBERG, $\mathrm{H}$. Aims and methods of vegetation ecology. New York: Wileyand Sons, 1974. 547 p.

NOCE, M. A.; SOUZA, I. F.; KARAM, D.; FRANÇA, A. C. Dinâmica populacional de plantas daninhas no milho (Zea mays), sob influência de palhadas de gramíneas forrageiras. In: Embrapa Milho e Sorgo-Artigo em anais de congresso (ALICE). In: Congresso Nacional de Milho e Sorgo, 27.; Simpósio Brasileiro sobre a Lagarta-do-cartucho, Spodoptera frugiperda, 3.; Workshop sobre Manejo e Etiologia da Mancha Branca do Milho, 2008, Londrina. Agroenergia, produção de alimentos e mudanças climáticas: desafios para milho e sorgo: trabalhos e palestras. [Londrina]: IAPAR; [Sete Lagoas]: Embrapa Milho e Sorgo, 2008. Disponível em: $<$ https://ainfo.cnptia.embrapa.br/digital/bitstream/item/30080/1/Dinamicapopulacional.pdf>.

SALES, A.; SILVA, A. R.; VELOSO, C. A. C.; MIRANDA, B. M. Desempenho do mogno africano (Khaya ivorensis A. Chev.) no sistema ILPF em Terra Alta-PA. In: SIMPÓSIO DE ESTUDOS E PESQUISAS EM CIÊNCIAS AMBIENTAIS NA AMAZÔNIA, 6., 2017, Belém. Embrapa Amazônia Oriental. Artigo em Anais de Congresso (ALICE). Belém: Uepa, 2017. v. 6, p. 1 - 7. Disponível em: $<$ https://ainfo.cnptia.embrapa.br/digital/bitstream/item/171260/1/anais-tcompletosimposio-2017-volume-1-01.pdf>.

SOUZA, A. G. V.; SANTOS, T. E. B.; MARIANO, T. P. B.; D'ABADIA, K. L.; BUENO, L. L.; FARIA, L. O.; SILVA, A. Incorporação do carbono pela comunidade microbiana do solo em função das diferentes espécies gramíneas no sistema ILPF. In: CONGRESSO DE ENSINO, PESQUISA E EXTENSÃO DA UEG, 4., 2018, Ipameri. Anais do Congresso de Ensino, Pesquisa e Extensão da UEG. Ipameri: UEG, 2018. v. $\quad 4, \quad$ p. $\quad 1-5 . \quad$ Disponível em: <http://www.cdn2.ueg.br/inscricao/35033/Enviar_para_CEPE_35033_162921.pdf>.

VOLL, E.; KARAM, D.; GAZZIERO, D. L. P. Dinâmica de populações de trapoeraba (Commelina benghalensis L.) sob manejos de solo e de herbicidas. Pesquisa Agropecuária Brasileira, Brasília-GO, v. 32, n. 6, p. 571-578, 1997. Disponível em: $<$ https://ainfo.cnptia.embrapa.br/digital/bitstream/item/92309/1/Pab12895.pdf>. 